\title{
Textualização de excertos do tratado Alguns pensamentos sobre a educação, de John Locke: análise das escolhas tradutórias com base nos níveis ideacional, interpessoal e textual
}

\author{
Débora Montenegro Pasin ${ }^{1}$ \\ Heloísa Orsi Koch \\ Delgado $^{2}$
}

\begin{abstract}
Resumo: Ao escrever um texto, o escritor, apesar de estar livre para trilhar suas linhas, passa por uma série de restrições que limitam seu movimento textual, como a memória de textos anteriores (todos os textos parecem estar relacionados de alguma forma) e as normas culturais internalizadas. Diferentemente do autor de um texto fonte, o tradutor não está limitado somente pela gramática, pelos padrões lexicais e pela sua habilidade quanto textualizador, mas sofre, também, restrições impostas pela mensagem pré-existente - o texto de chegada deve ter alto grau de semelhança com aquele de partida para que seja reconhecido como uma tradução. As escolhas do tradutor para atingir essa equivalência são inúmeras e cruciais para a construção do novo texto (textualização). Nessa perspectiva, o presente artigo tem como objetivo expor e comentar as escolhas tradutórias das autoras com base nos níveis ideacional, interpessoal e textual quando da tradução do par inglês/ português brasileiro de excertos de um dos mais famosos tratados escritos pelo filósofo inglês John Locke, Alguns Pensamentos sobre a Educação, extraídos da enciclopédia online Wikipédia.
\end{abstract}

Palavras-chave: Textualização. Escolhas tradutórias. Equivalência. John Locke.

Excerpts from the treatise called some thoughts concerning education, by John Lock: analysis of translation choices based on ideational, interpesonal and textual levels

\begin{abstract}
While writing a text, the writer, despite of being free to write his lines, he goes through a series of constraints that limit his text, such as the memory of previous texts (all texts seem to be related somehow) and the internalized cultural standards. Unlike the author of a source text, the translator is not only limited by grammar, lexical patterns and his ability as a textualiser, but also has to deal with the restrictions imposed by the pre-existing message - the target text should have a high degree of similarity with the source one in order to be recognized as a translation. The choices of the translator in order to achieve such equivalence are numerous and crucial for the construction of a new text (textualization). From this perspective, this article aims at exposing and commenting the translation choices of the authors based on the ideational, interpersonal and textual levels when translating, from English to Portuguese, excerpts of one of the most famous treatises written by the English philosopher John Locke, Some Thoughts Concerning Education, extracted from the online encyclopedia Wikipedia.
\end{abstract}

\footnotetext{
${ }^{1}$ Especialista em Estudos da Tradução pela Pontifícia Universidade Católica do Rio Grande do Sul. Coordenadora e professora do curso de idiomas SD Language Office. Telefone: 51. 8199.3666. E-mail: debora@sdlanguageoffice.com.br

${ }^{2}$ Professora Adjunta da Faculdade de Letras da Pontifícia Universidade Católica do Rio Grande do Sul. Coordenadora do Departamento de Letras Estrangeiras. Coordenadora da área de Língua Inglesa no Programa Institucional de Bolsa de Iniciação à Docência (PIBID/CAPES/PUCRS). E-mail: heloisa.delgado@pucrs.br.
} 
Keywords: Textualization. Translation choices. Equivalence. John Locke.

\section{Introdução}

Segundo Costa (2005, p. 26), "Todos os textos parecem ser, de uma forma ou de outra, dependentes de outros textos". Por mais livre que o escritor de um texto original pareça estar ao escrever, ele sempre encontrará uma série de restrições limitadoras do seu movimento textual, seja a memória de textos já lidos ou conceitos culturais já internalizados.

Essa realidade do escritor, no entanto, não se aplica à realidade do tradutor, pois o texto que este escrever será baseado numa mensagem já existente, em forma de texto, em outra língua, ou seja, este será dependente de outro, de um modo bastante peculiar.

De acordo com Costa,

o tradutor cria o texto não a partir do seu próprio ideacional, mas a partir de outro texto, ele não está limitado apenas pela gramática, pelos padrões lexicais da sua língua e pela sua habilidade como textualizador, mas sofre, principalmente, com as restrições impostas pelo texto préexistente, pelo seu tom e conteúdo, com os quais ele pode não estar de acordo, assim como impostas pela organização textual, ainda que em outro código (COSTA, 2005, p. 30).

Seguindo essa premissa, entendemos que o tradutor execute sua tarefa em condições diversas, pois seu texto alvo deve ter alto grau de semelhança com sua fonte correspondente para que seja reconhecido como uma tradução. Nos estudos da tradução, essa semelhança é denominada equivalência (COSTA, 2005, p. 26). As escolhas do tradutor para atingir essa equivalência são inúmeras e cruciais para a construção do novo texto (textualização). Tanto é crucial que a maior parte da literatura especializada sobre tradução dedica-se aos problemas relacionados à equivalência; porém, a maioria dos teóricos preocupa-se em sugerir, muitas vezes ditar, regras ou modos como os itens e as frases devam ser traduzidos em vez de explicar como e por que foram traduzidos de fato.

Nessa perspectiva, o presente artigo tem como objetivo expor e comentar as escolhas tradutórias das autoras com base nos níveis ideacional, interpessoal e textual quando da tradução do par inglês/ português brasileiro de excertos de um dos mais 
famosos tratados escritos pelo filósofo inglês John Locke ${ }^{3}$, Alguns Pensamentos sobre a Educação, extraídos da enciclopédia online Wikipédia ${ }^{4}$. Texto esse escolhido devido à representatividade da obra, cuja versão lusófona é, até então, inexistente, aliada à visibilidade da ferramenta em questão (apesar de muitos ainda menosprezarem seu uso) e o seu alcance mundial, em termos numéricos, no que tange a disseminação de conhecimento.

No decorrer do presente artigo, tais escolhas tradutórias estarão expostas em tabelas divididas em três quadros distintos: a) texto fonte; b) texto traduzido; e c) comentários.

\section{O texto traduzido como retextualização}

Esta seção trata dos aspectos envolvidos ao se traduzir um texto e traz exemplos ilustrativos, tirados do texto fonte em inglês (doravante TF) e do texto alvo traduzido para a língua portuguesa brasileira (doravante TT), referentes a esses aspectos.

Como já vimos, Costa (2005, p. 26) define o que chama de a dupla face da equivalência, que envolve duas realidades diferentes: a do escritor e a do tradutor. $\mathrm{O}$ escritor, ao elaborar um texto está, em princípio, livre para organizar um conjunto de palavras, orações e parágrafos de acordo com suas intenções e habilidades. Essa realidade do escritor, no entanto, não se aplica à realidade do tradutor, pois o texto que este escrever será baseado numa mensagem já existente em outra língua, ou seja, este será dependente de outro, de um modo bastante peculiar. $\mathrm{O} \mathrm{TF}$, portanto, limita o novo texto de inúmeras maneiras, sendo a mais visível delas o fato de que o TT deve possuir um alto grau de semelhança com seu correspondente original para que seja reconhecido como uma tradução. De acordo com o autor, muitas definições para equivalência têm sido apresentadas. Como afirma Toury (1980, p.37), “a equivalência tradutória ocorre quando um texto (ou item) na língua fonte e um texto (ou item) na língua alvo são relacionáveis às mesmas características relevantes (ou pelo menos a algumas dessas características" ${ }^{4}$.

\footnotetext{
${ }^{3}$ Considerado dos pensadores iluministas mais influentes e é conhecido como o Pai do Liberalismo Clássico; além disso, é tido como o protagonista do empirismo. ${ }^{4}$ Texto participante do Programa de Educação da Wikipédia.

${ }^{4}$ Texto fonte em inglês: "Translation equivalence occurs when a SI, and a TL text (or item) are relatable to (at least some of) the same relevant features".
} 
Essa definição tem a vantagem de considerar a tradução como um fenômeno que envolve não somente itens isolados, mas textos. Porém, a definição de Toury oferece uma ideia muito abrangente e não permite distinção entre tradução e adaptação (um texto inspirado em um texto original, mas não controlado por este).

Nesse sentido, Mason propõe uma emenda pequena, porém essencial, à definição de Toury:

a equivalência tradutória ocorre quando um texto (ou item) na LF (língua fonte) e um texto (ou item) na LA (língua alvo) são relacionáveis a maior parte das mesmas características relevantes. Tenho consciência de que "a maior parte" é uma expressão vaga, mas penso que esta é uma vagueza com a qual teremos que conviver (MASON, 1984, p. 209). ${ }^{5}$

Conforme Costa (2005, p. 27), ao lidar com equivalência, "é necessário distinguir dois momentos: a equivalência dos itens no nível da oração, ou equivalência propriamente dita, e a equivalência em nível (macro)textual: as escolhas do tradutor são substancialmente restritas no primeiro caso e múltiplas no segundo". Ambos os níveis de equivalência (nível da oração e nível do texto) são, sem dúvida, centrais a qualquer tradução. Seguindo Coulthard (1987, p. 181), “o processo de construção de um novo texto e seu produto de textualização",6.

Ainda conforme Costa (2005, p. 30), “o processo tradutório é mais bem compreendido quando reconhecemos esses dois níveis e os seus problemas inerentes".

Como esses momentos se encontram necessariamente interligados, "não é de se estranhar que o mais visível (o da equivalência propriamente dita) tenha recebido o grosso da atenção crítica até o momento" (COSTA, 2005, p. 30). Salienta, ainda, que "a maioria dos teóricos e críticos tende a sugerir ou ditar os modos como os itens e as frases devem ser

\footnotetext{
${ }^{5}$ Texto fonte em inglês: no"I propose to amend Toury's definition of translation equivalence ... to the following: "Translation equivalence occurs when a SL and a TL text (or item) are relatable to (most of) the same relevant features. "I am aware that "most of" is a vague term, but I think that this is a vagueness we shall have to live with".

${ }^{6}$ Texto fonte em inglês: "I will call this process, and the product thereof, textualisation".
} 
traduzidos em vez de explicar como e por que esses itens e frases foram traduzidos de fato" (COSTA, 2005, p. 30).

$\mathrm{Na}$ verdade, a tradução revela, de forma marcante, um aspecto que parece estar presente em todos os textos: logo que são criados, começam uma vida independente, de tal modo que sua interpretação e, dessa forma, o seu valor dependem apenas parcialmente das intenções originais do autor.

Para Costa (2005, p. 27), o TT é visto como uma entidade ao mesmo tempo dependente e autônoma. O plano dependente corresponde ao seu aspecto enquanto tradução e investigá-lo significa examinar minuciosamente o relacionamento de um dado par de línguas em nível sistêmico: as idiossincrasias gramaticais e lexicais, assim como as incongruências e incompatibilidades entre os dois sistemas. O plano autônomo do TT, por outro lado, corresponde ao seu aspecto enquanto texto, ou seja, ao modo como estão agrupadas as unidades (coesão e coerência entre palavras, orações, parágrafos, etc.).

Para compreender melhor o processo tradutório e seus produtos, fazem-se necessárias algumas considerações iniciais, tais como o entendimento das relações que ocorrem entre os níveis ideacional, interpessoal e textual, que permeiam todos os tipos de tex to em toda e qualquer língua.

Vejamos, então, o que cada um desses níveis representa.

\section{O Plano Ideacional e Interpessoal}

Parece não haver outra maneira de se produzir um texto a não ser partindo do ideacional para chegar ao textual, o que, em outras palavras, significa começar com um conjunto de significados para que seja possível produzir um texto que, por sua vez, constitui um novo conjunto de significados (COSTA, 2005, p. 34).

Parece ao autor que, em cada texto, há determinados blocos ideacionais que são mais importantes do que outros para o sentido global. Ele explica essa ideia com a definição de Hoey (1991, p. 47): "a primeira frase de um relatório costuma ter um status especial de frase resumo, por isso, seria possível argumentar que a capacidade da frase 1 
de fazer sentido junto com as outras frases do texto é resultado desse status especial"7, complementando-a com sua própria reflexão: "identificar o bloco ideacional que resume o sentido geral do texto seria muito útil, já que, conforme Coulthard, o que precisamos inicialmente é um resumo do conteúdo ideacional” (COSTA, 2005, p. 29).

Abaixo, como exemplo do exposto até aqui:

\section{Tab. 1 - Blocos ideacionais}

TF - "Some Thoughts Concerning Education" is a 1693 treatise on the education of gentlemen written by the English philosopher John Locke. For over a century, it was the

most important philosophical work on education in England. It was translated into almost all of the major written European languages during the eighteenth century, and nearly every European writer on education after Locke, including Jean-Jacques Rousseau, acknowledged its influence.

TT - A obra Alguns Pensamentos sobre a Educação é um tratado de 1693 relativo à educação de jovens nobres escrito pelo filósofo inglês John Locke. Por mais de um século, foi a obra filosófica sobre educação mais importante na Inglaterra. Traduzida em quase todas as principais línguas escritas europeias durante o século XVIII, e quase todos os escritores europeus que escreveram sobre educação depois de Locke, incluindo JeanJacques Rousseau, reconheceram sua influência.

\section{Comentários:}

Compreendemos que esse parágrafo determina a compreensão dos blocos ideacionais posteriores ao texto, pois carrega consigo o nome do título do tratado além de informações sobre esse, que conduzem o leitor à importância do trabalho de Locke e ativam, parecenos, uma curiosidade acerca do trabalho desenvolvido por ele.

No que diz respeito à textualização realizada com base no relacionamento sistêmico (idiossincrasias e incompatibilidades gramatical e/ou lexical entre as línguas envolvidas), podemos dizer que a escolha por "jovens nobres", por exemplo, deu-se devido à forma como o termo gentlemen era utilizado à época na qual o tratado foi escrito (dessa forma, não comportando o equivalente literal direto, cavalheiros; mas sim, aos jovens nobres que pertenciam às classes ricas). Nesse caso, tivemos que levar

\footnotetext{
7 Texto fonte em inglês: "The first sentence of a factual report often has a special status as a summarizing sentence. It could therefore be argued that the ability of sentence 1 to make sense with other sentences in the text is the result of this special status".
} 
em consideração os aspectos históricos e culturais da época, critério essencial a ser utilizado quando tratamos, principalmente, de tradução literária.

Construir um novo conjunto de significados é uma das maiores dificuldades enfrentadas pela tradução humana (assim como por aquela automática, sem dúvida), pois a passagem de significados de uma língua para outra não é tarefa fácil. Seria menos complicado, sem dúvida, se houvesse um sistema (ou se pudéssemos criá-lo) de

“correspondências biunívocas" (COSTA, 2005, p. 34), que nos permitisse partir do texto para o significado e do significado para o novo texto sem nenhum obstáculo.

Uma textualização estará inadequada quando a mensagem não for facilmente compreendida pelo público pretendido. No caso de textos traduzidos, é importante que o elemento interpessoal seja posto em prática, ou seja, que o tipo de público-leitor seja considerado (para este trabalho, imaginamos o estudante da disciplina de literatura do curso de Letras). Nesse caso, partes do ideacional podem ser expandidas ou contraídas conforme esse público. De acordo com Coulthard:

é o "interpessoal", ou o senso de público, o que nos permite, como escritores, manter o ideacional dentro de limites administráveis, sendo a interface ideacional/interpessoal o que causa as maiores dificuldades para os escritores de todas as idades e graus de maestria. Sem um claro senso de público, é impossível fazer as escolhas corretas a partir do ideacional (COULTHARD, 1987, p. 184-185). ${ }^{8}$

Dessa forma, podemos dizer que o número de variáveis na textualização da interface ideacional/ interpessoal é grande e, em alguns textos (longos e complexos), provavelmente infinito.

\section{O Plano Textual}

Textualizar, como conceituado anteriormente, significa construir um novo texto e implica diferentes dificuldades, tais como o sequenciamento, que diz respeito à ordem

\footnotetext{
${ }^{8}$ Texto fonte em inglês: "It is the "interpersonal", or sense of audience, which allows us as writers to keep the ideational within manageable limits and it is the ideational/interpersonal interface which causes most difficulties for writers of all ages and abilities. Without a clear sense of audience, it is impossible to make the right selections from the ideational."
} 
cronológica; a sinalização, que se relaciona com a gramática; e o registro, referente ao nível lexical.

De modo geral, há certos padrões sequenciais que são universais e outros mais específicos de certas culturas, assim como existem padrões sequenciais específicos de certos gêneros, como um romance (linguagem literária) ou um artigo científico (linguagem especializada). O tradutor necessariamente trabalha numa sequência, pois naturalmente traduz oração por oração, grupo por grupo e, por vezes, palavra por palavra. Nesse sentido, entendemos que a maioria dos tradutores trabalha com as menores unidades do discurso e preocupam-se mais com a frase ou a oração do que com a assimilação do ideacional do texto inteiro. Ao se utilizar dessa estratégia, o texto traduzido poderá apresentar limitações de ordem (macro)textual, como coesão e relações de correspondência. Nas palavras de Costa:

devido à reduzida capacidade de armazenamento da memória de curto prazo, lidar com elementos sequenciadores é um ato extremamente restrito na conversa informal. Pouco surpreende, portanto, que os textualizadores inexperientes tenham dificuldades com o uso da sinalização (COSTA, 2005, p. 39).

Ao contrário do sequenciamento, que é um traço onipresente em qualquer textualização, a sinalização (que diz respeito à gramática) varia segundo os hábitos e as habilidades do textualizador, conforme apontado por Coulthard:

(...) a reunião de orações num texto em si cria relações entre as orações; mas uma decisão secundária do escritor é sinalizar ou não essas relações por realização lexical. Se ele escolhe não fazê-lo, permitirá a possibilidade de ambiguidade ou mal entendido (COULTHARD, 1987, p. 187). ${ }^{9}$

Vejamos a tabela seguinte (Tab. 2) sobre sinalizações.

\footnotetext{
${ }^{9}$ Texto fonte em inglês: "(...)The placing of clauses together in a text in itself creates relationships between clauses; but a secondary writer's decision is whether to signal these relationships by lexical realisation. If (s)he chooses not to, (s)he allows the possibility of ambiguity or misunderstanding."
} 
Tab. 2 - Sinalizações

TF - In his Essay Concerning Human Understanding (1690), Locke outlined a new theory of mind, contending that the gentleman's mind was a tabula rasa or "blank slate"; that is, it did not contain any innate ideas. Some Thoughts Concerning Education explains how to educate that mind using three distinct methods: the development of a healthy body; the formation of a virtuous character; and the choice of an appropriate academic curriculum. TT - Em seu Ensaio Acerca do Entendimento Humano (1690), Locke esboçou uma nova teoria da mente, afirmando que a mente de um jovem era uma tabula rasa ou um

"quadro em branco"; isto é, não continha ideias inatas. Alguns Pensamentos sobre a Educação explica como educar essa mente usando três métodos distintos: o desenvolvimento de um corpo saudável; a formação de um caráter virtuoso; e a escolha de um currículo acadêmico apropriado.

\section{Comentários:}

Com relação à escolha da preposição (nível lexical), optamos por acerca devido ao número maior de ocorrências dessa preposição por meio de pesquisas em textos literários (de Locke e de outros) e na internet.

O verbo outline possui quatro significados diferentes, mas utilizamos esboçar por se tratar do verbo mais usado em se tratando de uma nova teoria (em processo de 
entendimento, já que uma teoria tenta explicar algo de difícil concretização).

Tabula rasa não foi traduzida, pois se trata de uma expressão latina, comumente aplicada no campo da Psicologia no mundo inteiro.

Com relação ao segmento did not contain any, optamos por não utilizar o negativo duplo no português (not = não $/$ any $=$ qualquer ou nenhum), evitando ambiguidade (any = qualquer ou nenhum), já que não havia necessidade da ênfase.

Falemos, agora, sobre o que Sinclair (1991, p. 8) chama de "princípio da livre escolha" e "princípio idiomático". O autor defende a ideia de que, para explicar o modo como o significado surge a partir do texto linguístico, teremos que desenvolver dois princípios de interpretação diferentes.

O primeiro trata o texto linguístico como resultado de um número grande de escolhas complexas. Em cada ponto em que uma unidade está completa (uma palavra, um sintagma ou uma oração), abre-se uma ampla variedade de escolhas, e a única restrição é a gramaticalidade. Este princípio é formado por dois tipos de escolha: a lexical e a gramatical.

Vejamos as seguintes tabelas (Tab. 3, Tab. 4 e Tab. 5).

\section{Tab. 3 - Princípio da escolha lexical}

TF - Rather than writing a wholly original philosophy of education, Locke, it seems, deliberately attempted to popularise several strands of seventeenth-century educational reform at the same time as introducing his own ideas. English writers such as John

Evelyn, John Aubrey, John Eachard, and John Milton had previously advocated "similar reforms in curriculum and teaching methods," but they had not succeeded in reaching a wide audience. Curiously, though, Locke proclaims throughout his text that his is a revolutionary work; as Nathan Tarcov, who has written an entire volume on Some Thoughts, has pointed out, "Locke frequently explicitly opposes his recommendations to the 'usual,' 'common,' 'ordinary,' or 'general' education." 
TT - Ao invés de escrever uma filosofia inédita da educação, Locke, ao que parece, tentou popularizar, deliberadamente, várias vertentes da reforma educacional do século XVII ao mesmo tempo em que introduzia suas próprias ideias. Escritores ingleses como John Evelyn, John Aubrey, John Eachard, e John Milton já tinham defendido "reformas semelhantes no currículo e nos métodos de ensino", mas eles não conseguiram chegar a um vasto público. Curiosamente, porém, Locke proclama, ao longo de seu texto, que o seu é um trabalho revolucionário; como observou Nathan Tarcov, que escreveu um volume inteiro sobre Alguns Pensamentos, "Locke frequente e explicitamente opõe suas recomendações à educação 'habitual', 'comum', 'normal', ou 'geral'.

\section{Comentários:}

Com relação ao princípio da livre escolha lexical, citamos três exemplos:

O primeiro refere-se ao equivalente inédita para original. Embora essa palavra possa ser traduzida de diferentes maneiras no português brasileiro, selecionamos inédita devido a sua relação com o campo da filosofia.

O segundo, aos equivalentes de usual e common, habitual e normal. O obstáculo, em nossa experiência, foi a tentativa de não fornecemos uma equivalência direta literal uma vez que as palavras, no TF, possuem significados similares, dependendo do contex to em que se encontram.

O terceiro refere-se à ordinary, cujos significados são ambíguos, sendo um deles, negativo.

\section{Tab. 4 - Princípio da livre escolha (gramatical)}

TF - As England became increasingly mercantilist and secularist, the humanist educational values of the Renaissance, which had enshrined scholasticism, came to be regarded by many as irrelevant.

TT - Na medida em que a Inglaterra se tornava cada vez mais mercantilista e secularista, os valores educacionais humanistas do Renascimento, os quais consagram à escolástica, passaram a ser considerados irrelevantes por muitos.

\section{Comentários:}

O tempo verbal apresentado em became (pretérito perfeito) foi transformado em pretérito imperfeito (se tornava ao invés de se tornou) para garantir coerência temporal com o uso da conjunção as ou, na versão em português brasileiro, na medida em que. 


\section{Tab. 5 - Princípio da livre escolha (lexical e gramatical)}

TF - Although Locke revised and expanded the text five times before he died, he never
substantially altered the "familiar and friendly style of the work." The "Preface" alerted
the reader to its humble origins as a series of letters and, according to Nathan Tarcov, who
has written an entire volume on Some Thoughts, advice that otherwise, might have
appeared "meddlesome" became welcome. Tarcov claims Locke treated his readers as his
friends and they responded in kind.

TT- Embora Locke tenha revisado e ampliado o texto cinco vezes antes de morrer, ele nunca alterou substancialmente o "estilo familiar e amigável do trabalho". O "Prefácio" alertava o leitor para sua origem humilde como uma série de cartas e, de acordo com Nathan Tarcov, que escreveu um inteiro volume sobre Alguns Pensamentos, os conselhos que, expressos de outra forma, poderiam parecer "inoportunos", passaram a ser bem recebidos. Tarcov afirma que Locke tratava seus leitores como seus amigos, e eles respondiam na mesma moeda.

\section{Comentários:}

Os verbos no passado simples revised e expanded foram traduzidos para o português brasileiro utilizando-se a estrutura verbo have + particípio, para garantir coerência temporal: Embora Locke tenha revisado e ampliado.

Quanto à expressão in kind, muitas são as possibilidades: dentre elas, a que semanticamente representa o desejo de reciprocidade do autor: na mesma moeda (= da mesma forma).

O segundo princípio - o princípio idiomático - diz que o usuário da língua dispõe de um grande número de sintagmas semi-pré-construídos que constituem opções unitárias, mesmo que possam parecer analisáveis em partes. Este é constituído de três conjuntos diferentes de escolhas mais amplas:
a) Expressões idiomáticas
b) Colocações
c) Sequências lexicogramaticais fixas 
Embora os dois princípios - o princípio da livre escolha e o princípio idiomático digam respeito às mesmas categorias linguísticas (léxico e gramática), a diferença essencial está no fato de que no princípio da livre escolha, a escolha é múltipla e, no principio idiomático, a escolha é unitária. Em uma tradução literal, o princípio idiomático tende a desempenhar um papel menor ou a estar ausente, com expressões idiomáticas e colocações naturais, ocorrendo apenas quando houver correspondência biunívoca entre as palavras das línguas envolvidas. 
Nosso trabalho pretende avaliar as traduções que dizem respeito às colocações. Vale lembrar que as colocações ${ }^{10}$ - exemplo que evidenciaremos abaixo - são formadas por uma base, a palavra de maior carga semântica, geralmente um substantivo, mais um colocado. O nome da colocação será derivado do colocado. Assim, uma colocação de verbo + substantivo será uma colocação verbal, um adjetivo + substantivo será uma colocação adjetiva, e um substantivo + substantivo será uma colocação nominal.

Tab. 6 - Princípio idiomático (colocações)

TF - Of Locke's major claims in the Essay Concerning Human Understanding and Some Thoughts Concerning Education, two played a defining role in eighteenth-century educational theory. The first is that education makes the man; as Locke writes at the opening of his treatise, "I think I may say that of all the men we meet with, nine parts of ten are what they are, good or evil, useful or not, by their education." In making this claim, Locke was arguing against_both the Augustinian view of man... In his Essay Locke posits an "empty" mind - a tabula rasa - that is "filled" by experience. In describing the mind in these terms, Locke was drawing on Plato's Theatetus, which suggests that the mind is like a "wax tablet".

TT - Das principais reivindicações de Locke no Ensaio Acerca o Entendimento Humano e Alguns Pensamentos sobre a Educação, duas tiveram um papel decisivo na teoria educacional do século XVIII. A primeira é que a educação faz o homem, como Locke escreve no início de seu tratado: "Creio que eu possa dizer que, de todos os homens com os quais nos deparamos, nove entre dez são o que são, bons ou maus, úteis ou não, devido a sua educação". Ao fazer esta afirmação, Locke estava argumentando tanto contra a visão agostiniana do homem... Em seu Ensaio, Locke postula uma mente "vazia" - a tabula rasa - isto é, "preenchida" pela experiência. Ao descrever a mente nesses termos, Locke estava recorrendo ao "Theatetus" de Platão, o qual sugere que a mente é como uma "tábua de cera".

\section{Comentários:}

De acordo com os sintagmas pré-definidos, encontramos as seguintes equivalências tradutórias de sentido na língua portuguesa brasileira:

Papel (substantivo $)+$ decisivo $($ colocado $)=$ colocação adjetiva Teoria $($ substantivo $)+$ educacional $($ colocado $)=$ colocação adjetiva fazer $($ verbo $)+$ esta afirmação $($ substantivo $)=$ colocação verbal mente

${ }^{10}$ Existem, na literatura, várias maneiras de denominar 'uma combinação de várias palavras', segundo diferentes autores. Biber et all (1998) optaram por lexical bundles e Nattinger e DeCarrico (1992), por lexical phrases, por exemplo. Nesta tese, optamos pela denominação colocação, utilizada por Hausmann (1985) e Tagnin (2005). 
$($ substantivo $)+$ vazia $($ adjetivo $)=$ colocação adjetiva

Todos os exemplos citados são úteis na medida em que ilustram a diferença, previamente citada, entre ambos os princípios: (1) no princípio da livre escolha, a escolha, como já diz o nome, é múltipla; (2) no princípio idiomático, a escolha é unitária.

“As traduções muitas vezes apresentam configurações divergentes do princípio da livre escolha ou do princípio idiomático" (COSTA, 2005, p. 42). Uma análise cuidadosa de ambos os princípios em ação pode ser útil para refinar a avaliação das traduções e, quem sabe, auxiliar no desenvolvimento uma pedagogia da tradução de textos literários que seja mais eficiente.

\section{Considerações Finais}

Partindo desse breve estudo sobre a construção de um novo texto oriundo do processo tradutório (textualização), podemos inferir que as escolhas tradutórias partem de uma necessidade de equivalência para que o texto em questão seja (re)conhecido como tradução.

Observamos também que o fenômeno tradutório envolve mensagens cujas características relevantes são relacionáveis, pois apesar de ser uma entidade autônoma (enquanto texto), o texto alvo é intimamente ligado à sua fonte, o que faz do tradutor "um tipo especial de escritor que cria o texto não a partir do seu próprio ideacional, mas a partir de outro préexistente" (COSTA, 2005, p. 30).

Cabe ressaltar, também, que cada língua carrega consigo sua própria verdade, portanto, as correspondências lexicais são sistematizáveis e dependem das tendências de cada idioma.

Entender como substituir um signo de partida por outro de chegada sem que o primeiro perca sua força, e que o segundo possa, a contento, exprimir o que o primeiro intencionou manifestar não é tarefa fácil; tendo essa concepção em mente, optamos por descrever nosso processo tradutório com o intuito de incrementar a pouca literatura existente a esse respeito. 
Por fim, sobre a árdua tarefa de traduzir, citemos Benjamin:

[...] tende a expressar o mais íntimo relacionamento das línguas entre si. Ela própria não é capaz de revelar, nem é capaz de instituir esta relação oculta; pode, porém, apresentá-la, atualizando-a de maneira germinal e intensiva. [...] Essa tarefa consiste em encontrar na língua para qual se traduz a intenção, a partir da qual o eco do original é nela despertado. (BENJAMIN, 2001, p.202)

\section{Referências}

BENJAMIN, W. A tarefa: renúncia do tradutor, in Clássicos da teoria da Tradução. vol 1. Florianópolis: UFSC, 2001. Trad. de Suzana Kampff Lages.

COSTA, W.C. O texto traduzido como re-textualização. Cadernos de Tradução, Florianópolis, v. 2, n. 16, p. 25-54, 2005.

COULTHARD, R M. Language Topics - Essays in Honour of Michael Halliday, Evaluative text analysis. R Steele \& T Treadgold (Orgs). Amsterdam: Benjamins, 1987.

HOEY, M P. Patterns of Lexis in Text. Oxford: Oxford University Press, 1991.

LOCKE, J. Wikipedia, a enciclopédia livre. Disponível em: <http://en.wikiquote.org/wiki/John_Locke>. Acesso entre 10 de agosto e 10 de setembro de 2014.

MASON K. Translation in Context. Tese de doutorado inédita. Birmingham: Universidade de Birmingham, 1984.

SINCLAIR, J. Corpus Concordance Collocation. Oxford: Oxford University Press, 1991.

TOURY, G. In Search of a Theory of Translation.: The Porter Institute for Poetics and Semiotics. Tel Aviv: Universidade de Tel Aviv, 1980.

Wikipedia Education Program. Wikipedia, a enciclopédia livre. Disponível em: <http://outreach.wikimedia.org/wiki/Wikipedia_Education_Program/History>. Acesso entre 10 de agosto e 10 de setembro de 2014.

Recebido em 30 de setembro de 2014 Aceito para a publicação em 18 de dezembro de 2014 